\title{
International Normalized Ratio of Prothrombin Time Level Finding
}

National Cancer Institute

\section{Source}

National Cancer Institute. International Normalized Ratio of Prothrombin Time Level

Finding. NCI Thesaurus. Code C157421.

A finding that indicates the international normalized ratio of prothrombin time level in a sample. 